\title{
Accelerated Long-Term Forgetting Limited to the Recollection Component of Recognition Memory in a Temporal Lobe Epileptic Patient
}

Giovanni Augusto Carlesimo, Antonio Daniele, Maria Giovanna Lombardi, Giordano Lacidogna, Alfredo La Cara, Lucia Fadda \& Carlo Caltagirone

To cite this article: Giovanni Augusto Carlesimo, Antonio Daniele, Maria Giovanna Lombardi, Giordano Lacidogna, Alfredo La Cara, Lucia Fadda \& Carlo Caltagirone (2017) Accelerated LongTerm Forgetting Limited to the Recollection Component of Recognition Memory in a Temporal Lobe Epileptic Patient, Neurocase, 23:5-6, 278-286, DOI: 10.1080/13554794.2017.1390141

To link to this article: https://doi.org/10.1080/13554794.2017.1390141

Published online: 26 Oct 2017.

Submit your article to this journal $[\pi$

Џ Article views: 44

Q View related articles $\longleftarrow$

View Crossmark data ־ 


\title{
Accelerated Long-Term Forgetting Limited to the Recollection Component of Recognition Memory in a Temporal Lobe Epileptic Patient
}

\author{
Giovanni Augusto Carlesimo*a,b, Antonio Daniele*c, Maria Giovanna Lombardi ${ }^{\mathrm{b}}$, Giordano Lacidognac, \\ Alfredo La Cara ${ }^{d}$, Lucia Fadda ${ }^{\mathrm{a}, \mathrm{b}}$ and Carlo Caltagirone ${ }^{\mathrm{a}, \mathrm{b}}$

\begin{abstract}
aDepartment of Systems Medicine, "Tor Vergata" University, Rome, Italy; ${ }^{b}$ Unit of Clinical and Behavioural Neurology, IRCCS Santa Lucia Foundation, Rome, Italy; 'Centre for Neuropsychological research, Institute of Neurology- Catholic University, Rome, Italy; ${ }^{\mathrm{d}}$ Neurophysiopathology Unit, Tivoli hospital, Tivoli, Italy
\end{abstract}

\section{ABSTRACT}

Accelerated long-term forgetting (ALF) is a frequent finding in patients with temporal lobe epilepsy (TLE). Here we report the case of a TLE patient who complained of marked difficulties in remembering personal events and information even though repeated neuropsychological assessments had failed to detect any deficit on common laboratory memory tests. The patient underwent an experimental investigation that involved estimating recollection and familiarity processes in the performance on verbal and visual recognition tests, over intervals ranging from 10 minutes to 7 days. Results showed accelerated forgetting confined to the recollection component only, which was particularly evident in the verbal test.
ARTICLE HISTORY

Received 21 June 2017 Accepted 4 October 2017

KEYWORDS

Accelerated long-term forgetting; temporal lobe epilepsy; declarative memory; amnesia; recollection

\section{Introduction}

The classical amnesic syndrome, due to damage affecting cortical areas in the mesial temporal lobe (MTL) or interconnected subcortical structures in the diencephalon, is characterized by failure to form new traces in declarative memory. Consequently, these patients are deficient in recalling or recognizing the memorandum from the very first few seconds following exposure to the information to be learnt (Insausti, Annese, Amaral, \& Squire, 2013). Consistent with this general framework, laboratory tests commonly used to investigate declarative memory in clinical contexts assess recall or recognition for verbal or visuo-spatial stimuli following delays ranging from few seconds to a maximum of 30 min (Lezak, Howieson, \& Loring, 2004). Interestingly, most of the studies that have assessed memory performance over longer delays (ranging from $1 \mathrm{~h}$ to several weeks) with recognition tests have found that in these patients the forgetting curve (representing memory loss as a function of the passing of time) was similar to that of normal controls (e.g., McKee \& Squire, 1992; see, for partially discordant results, Freed \& Corkin, 1988). This strengthens the belief that the critical deficit in the classical amnesic syndrome is a failure to store new memory traces. Once the memory trace is formed, however, the subsequent neurobiological mechanisms responsible for long-term consolidation function normally.

In the last few years, a new amnesic syndrome has been described that is characterized by normal performance on classical declarative memory tests (i.e., tests delivered at delays no longer than $30 \mathrm{~min}$.), but impaired recall or recognition at longer delays. This condition, which is known as long-term amnesia (Mayes et al., 2003) or accelerated long-term forgetting (ALF; Blake, Wroe, Breen, \& McCarthy, 2000), has been typically described in patients with temporal lobe epilepsy (TLE) (for reviews see Elliott, Isaac, \& Muhlert, 2014; Fitzgerald, Mohamed, Ricci, Thayer, \& Miller, 2013). Several reports have described single cases (Lucchelli \& Spinnler, 1998; Mayes et al., 2003) or groups of TLE patients (Blake et al., 2000; Cassel, Morris, Koutroumanidis, \& Kopelman, 2016) who performed as well as normal controls on tests of recall and/or recognition administered at commonly used delays in routine neuropsychological assessments, but considerably worse than normal controls on analogous tests delivered at delays ranging from $1 \mathrm{~h}$ to 8 weeks. As a result, the forgetting curves in the time frame passing from short to long delay tests were markedly steeper in these patients as compared to healthy controls, which suggest that in these patients the critical deficit was failure to consolidate the memory trace following normal initial storage.

An interesting question is whether ALF in TLE patients is related to the modality of the to-be remembered material (whether verbal or visual), according to the side of the epileptic focus. Indeed, in line with the "material specificity hypothesis" (Milner, 1968), it is generally agreed that the right and left MTLs underlie episodic memory as a function of the visual or verbal nature of the memorandum, respectively. Accordingly, patients with lateralized damage in the MTL display a modality specific memory loss, verbal in case of left damage, visuospatial in case of right damage. More recent findings report, however, that the link between material modality and side of 
the MTL lesion mainly holds for the verbal material/left MTL, but less consistently for the visual material/right MTL (Barr, 1997; Lee, Yip, \& Jones-Gotman, 2002). Results of the literature on ALF at this regard are sparse and inconclusive. Indeed, the increased forgetting in these patients is generally irrespective of the verbal or visual modality of the to-be remembered material. The description in few cases of increased forgetting for verbal, but not visual material (Davidson et al., 2007; Lucchelli \& Spinnler, 1998; Manes et al., 2005) is controversial (Butler and Zeman, 2008) and in any case it was related to the side of the epileptic abnormalities (left temporal anterior focus) only in one case (Lucchelli \& Spinnler, 1998).

In the last two decades, the existence of two ways in which recognition memory might operate has been one of the most investigated issues in human declarative episodic memory. In one case, exposure to a previously encountered item cues recollection of a number of contextual, temporal and other pieces of associative information that makes the experience of retrieval vivid, such as reliving the event with the mind's eye. In other cases, by contrast, the item is recognized as having been previously encountered but does not cue any associative information, so the act of remembering is just made up of a feeling of familiarity. These two recognition memory processes are generally defined as recollection and familiarity (Montaldi \& Mayes, 2010; Wixted, Mickes, \& Squire, 2010; Yonelinas, 2002). According to the advocates of the so called dual-process theory (e.g., Montaldi \& Mayes, 2010; Yonelinas, Kroll, Dobbins, Lazzara, \& Knight, 1998), the memory processes that underlie recollection and familiarity are qualitatively different and this distinction is reflected by the fact that different neural substrates underlie the two processes. The search for such neurobiological substrates has focused on distinct cortical regions in the MTL. In particular, the hippocampus proper should support the cognitive operations that are necessary for recollection memory, whereas the perirhinal cortex (in the parahippocampal gyrus) should mediate familiarity processes. A reasonably large number of neuropsychological (e.g., Aggleton et al., 2005; Turriziani, Serra, Fadda, Caltagirone, \& Carlesimo, 2008) and functional neuroimaging (Montaldi, Spencer, Roberts, \& Mayes, 2006; Skinner \& Fernandes, 2007) evidence supports this position. ${ }^{1}$

Based on hypothetical distinction between the neurobiological mechanisms underlying the two recognition memory components, it would be relevant to investigate whether ALF in TLE patients involves recollection and familiarity information at a similar degree or whether it affects one of the two components more than the other. To our knowledge, no study involving TLE patients with ALF has addressed this issue so far. In the only study that considered distinct memory processes involved in the ALF of TLE patients, Tramoni et al. (2011) found accelerated forgetting at a 6-week delayed test for contextually-bound experiences, but not for context-free information (considered representative of episodic and semantic memory, respectively). Although these authors alluded to the possibility of preserved familiarity, but impaired recollection in their TLE patients, their memory paradigm was not suited for taking apart the contribution of the two components to overall recognition.
In this article, we report the case of a patient with drugresistant TLE, with an epileptic focus in the right temporal lobe and neuroimaging evidence of a focal damage in the head of the right hippocampus. After more than 10 years of frequently occurring complex partial seizures, the patient gradually started to experience marked difficulties in remembering personal events and information. Repeated neuropsychological assessments had failed to detect any impairment on standard tests of declarative memory. The patient underwent an experimental investigation that involved estimating recollection and familiarity processes in a recognition paradigm for verbal (words) and visual (unknown faces) materials over intervals ranging from $10 \mathrm{~min}$ to 7 days. As the anatomical lesion (and probably the epileptic focus) was confined to the hippocampus, we predicted that the accelerated forgetting in this patient could mainly involve the recollection component of recognition leaving substantially unaffected the familiarity component. As for the material (verbal vs visual) involved by the recollection deficit, we could not advance strong predictions, given the uncertainties of the literature (see above) and the fact that the epileptic abnormalities in EF had their source in the right side, but they showed a tendency towards contralateral diffusion.

\section{Case report}

\subsection{Case history}

EF was a 37-year-old woman with a university degree when she was first seen at the Memory Disorders Laboratory of our Hospital in December 2013. In addition to the daily occurrence of drug-resistant partial epileptic seizures, her main complaint was a memory impairment for both recent and remote events that insidiously appeared when she was about 27 years old and had become more notable since 2010, when she was about 35 years old. In 1992 (when the patient was 16 years old), she had the first epileptic seizure, which was characterized by turning movements of her head and eyes to the right and a brief (approximately two minutes) interruption of consciousness. In subsequent months, the patient experienced several other epileptic seizures with similar characteristics. When she was about 17 years old (at about the same time she started taking carbamazepine) the clinical characteristics of the seizures changed. Indeed, from 1993 up until this time, the seizures started with a gustatory hallucination (i.e., a bitter taste) associated with a subjective feeling of mental and physical wellbeing that the patient defined as "almost orgasmic". Following this phase, in which the patient often adequately answered questions, but with increased delay, she did not remember anything of subsequent events. The seizure manifestations could limit to the above described subjective phenomena or could be associated with additional features, such as verbal and/or gestural automatisms. At the end of the seizure, the patient appeared confused, slowed down and disoriented in space. Subsequently, she had reduced memory about events that occurred in the half hour following seizure resolution. In subsequent years the clinical characteristics of the seizures did not change, but the frequency of the seizures 
increased. Up until now, she has never had seizures characterized by experiences of déjà vu or seizures characterized by recurrent episodes of acute memory loss consistent with a diagnosis of transient epileptic amnesia. In 2007, the average frequency of her seizures was two per week. In subsequent years, particularly since about 2010, there has been a further increase in seizure frequency. At the time of our observation, seizures occurred with a frequency ranging from two to four per day (more rarely up to six seizures per day). Over time, the patient has taken several antiepileptic drugs (carbamazepine, lamotrigine, levetiracetam, phenobarbital, barbexaclone, sodium valproate, lacosamide) in monotherapy or together. When EF was assessed at the Memory Disorders Laboratory of our institute, she was taking carbamazepine $400 \mathrm{mg}$ t.i.d. and lacosamide $100 \mathrm{mg}$ b.i.d.. In 2010, when she was about 35 years old, the patient gradually began to have greater difficulty in remembering recent events and in recognizing people she had known recently, with marked effects on daily living activities, including her job and social duties. After the appearance of these memory complaints, the patient was usually able to remember a given event for several minutes or up to a few hours and afterwards forgot the event. Despite difficulty in obtaining reliable information from the patient and her relatives/friends about the approximate amount of time that passed before she forgot an event, they reported that in everyday life EF forgot what happened only several hours (sometimes approximately a day) after the occurrence of the event. In 2010, due to both the worsening of this memory impairment and to an increase in the frequency of epileptic seizures, the patient decided to quit her job as a tour guide because she realized that she was no longer able to carry out her duties. A video-EEG performed in 2011 documented slow epileptic abnormalities in the right temporal regions and recorded some seizures associated with motor automatisms whose EEG correlate was localized in the right temporal lobe. A polygraphic EEG exam performed in July 2012 documented interictal epileptic abnormalities in the right temporal regions with a tendency towards contralateral diffusion. Since when the patient came under our observation, her neurological examinations have been unremarkable.

\subsection{Neuroimaging}

Since February 1997, repeated cerebral MRI examinations have shown a swollen area of abnormal signal intensity (without a contrast enhancement after gadolinium-DTPA) in the head of the right hippocampus (Figure 1(a,b)), which did not change significantly in size and signal features over time. The mesencephalic cisterna and choroidal fissure were reduced in size, but no additional areas of abnormal signal intensity was evident in other cortical or subcortical brain structures. The most likely interpretation of this area of abnormal signal intensity is FCD.

A proton magnetic resonance spectroscopy (March 2011) showed an increase in choline (Cho) concentration in the lesion volume associated with a decrease in $\mathrm{N}$-acetyl-aspartate (NAA) concentration. This metabolic pattern is consistent with FCD, as recently shown in a series of patients with drugresistant epilepsy, including seven patients with neuropathologically confirmed FCD type II (Tschampa et al., 2015).

\subsection{Neuropsychological assessment}

From April 2011 to November 2013, the patient underwent repeated neuropsychological assessments. In the most recent of these evaluations (November 2013), patient's performance was assessed on tests of general intelligence, executive functions, visual-constructive abilities, short-term memory and declarative episodic memory. As can be seen in Table 1, confirming the results of previous assessments, EF obtained performance scores in the normal range on all tests of the neuropsychological battery. In particular, she obtained normal scores on tests that assessed verbal and visuo-spatial episodic long-term memory at delays ranging from few seconds to $30 \mathrm{~min}$. following the study phase.

\section{Experimental investigation}

\subsection{Word and face recognition tests}

We used a verbal (words) and a visual (unknown faces) version of the experimental paradigm devised by Huppert and Piercy (1978). The paradigm was modified to obtain, for each

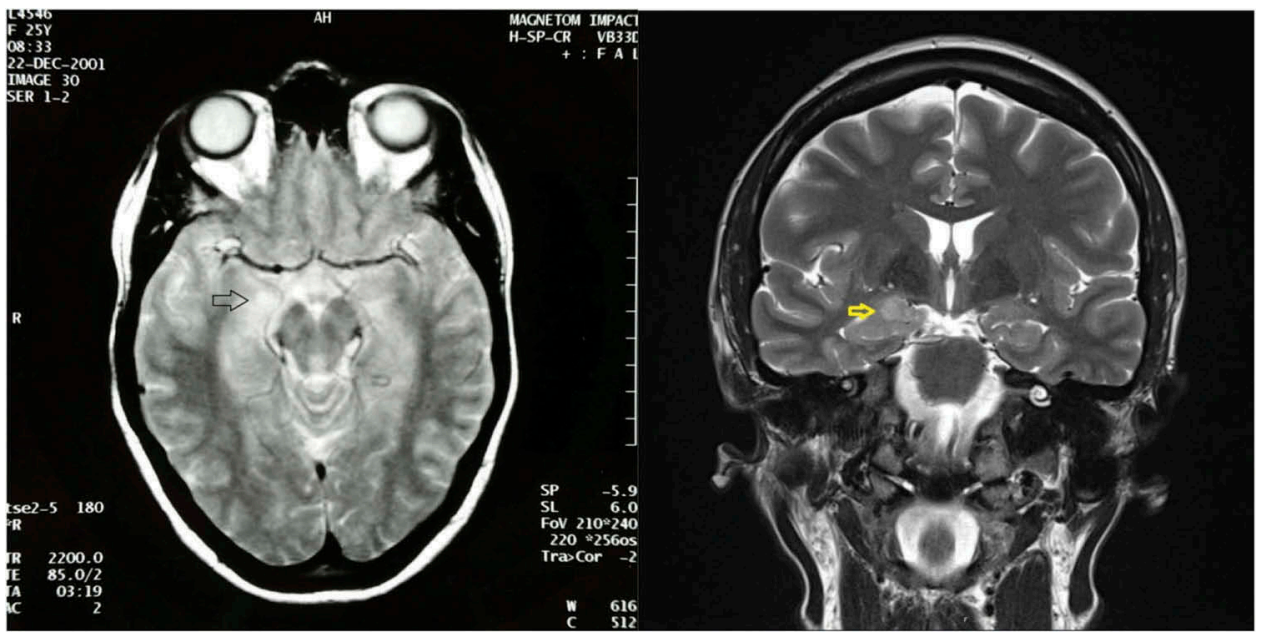

Figure 1. Axial T2-weighted MRI (December 2001; panel A) and coronal T2-weighted MRI (July 2012; panel B) showing an area of increased signal intensity in the head of the right hippocampus. 
Table 1. EF's performance scores on three neuropsychological assessments administered in three consecutive years. For all tests, scores adjusted for age, education and gender, normality cut-off scores (corresponding to a performance $\geq 95 \%$ of the lower tolerance limit of the normal population distribution) and percentiles with respect to the score distribution in the normative sample are reported (references in brackets).

\begin{tabular}{|c|c|c|c|c|c|c|}
\hline \multirow[b]{2}{*}{ Cognitive function } & \multirow[b]{2}{*}{ Test } & \multicolumn{3}{|c|}{ EF's assessment } & \multirow{2}{*}{$\begin{array}{l}\text { Maximum } \\
\text { score }\end{array}$} & \multirow{2}{*}{$\begin{array}{l}\text { Normality cut-off } \\
\text { score }\end{array}$} \\
\hline & & April 2011 & May 2012 & May 2013 & & \\
\hline General Intelligence & $\begin{array}{l}\text { Raven's Progressive } \\
\text { Matrices '47 (Carlesimo, } \\
\text { Caltagirone, \& Gainotti, } \\
\text { 1996) }\end{array}$ & $36(=100 \% 0)$ & $28.7(>75 \% 0)$ & $36(=100 \% 0)$ & 36 & $>19.0$ \\
\hline Verbal short-term memory & Digit span (Monaco, Costa, & $5.4(>25 \% 0)$ & $5.4(>25 \%)$ & $6.5(=100 \% 0)$ & 9 & $>4.26$ \\
\hline $\begin{array}{l}\text { Visuo-spatial short- term } \\
\text { memory }\end{array}$ & $\begin{array}{l}\text { Caltagirone, \& Carlesimo, } \\
2013 \text { ) } \\
\text { Corsi Block task (Monaco } \\
\text { et al., 2013) }\end{array}$ & $5.4(>50 \% 0)$ & $6.4(=100 \% 0)$ & $7.4(=100 \%)$ & 9 & $>3.46$ \\
\hline Verbal long-term memory & 15-word list (Carlesimo et al., & $59.7(=100 \%)$ & $56.7(=100 \%)$ & $59.7(=100 \%)$ & 75 & $>28.5$ \\
\hline $\begin{array}{l}\text { Visuo-spatial long-term } \\
\text { memory }\end{array}$ & $\begin{array}{l}1996) \\
\text { Immediate recall } \\
15^{\prime} \text { delayed recall } \\
\text { Recognition memory tests } \\
\text { battery (Smirni, Turriziani, } \\
\text { Olivieri, Smirni, \& Cipollotti, } \\
\text { 2010) } \\
\text { Words } \\
\text { Recognition memory tests } \\
\text { battery (Smirni et al., 2010) } \\
\text { Faces } \\
\text { Buildings } \\
\text { Supraspan spatial sequence } \\
\text { (Spinnler \& Tognoni, 1987) } \\
\text { Rey's Figure test (Caffarra, } \\
\text { Vezzadini, Dieci, Zonato, \& } \\
\text { Venneri, 2002) }\end{array}$ & $\begin{array}{c}10.5 \text { (=100\%) } \\
\text { N/A } \\
\text { N/A } \\
\text { N/A } \\
\text { N/A } \\
15.5(=100 \% 0)\end{array}$ & $\begin{array}{c}11.2(=100 \%) \\
\text { N/A } \\
\text { N/A } \\
\text { N/A } \\
\text { N/A } \\
15.5(=100 \%)\end{array}$ & $\begin{array}{c}15(=100 \%) \\
23.4(>10 \% 0) \\
26.7(>50 \% 0) \\
24.4(>25 \% 0) \\
9.4(>10 \% 0) \\
\text { N/A }\end{array}$ & $\begin{array}{c}15 \\
30 \\
30 \\
30 \\
30.8 \\
36\end{array}$ & $\begin{array}{r}>4.7 \\
>22.5 \\
>21.6 \\
>21.4 \\
>5.8 \\
>9.5\end{array}$ \\
\hline Executive functions & $\begin{array}{l}\text { Stroop test (Valgimigli et al., } \\
\text { 2010) } \\
\text { Word reading: time/errors } \\
\text { Color naming: time/errors } \\
\text { Interference time/errors } \\
\text { Color word Interference (time) } \\
\text { Color word Interference } \\
\text { (errors) } \\
\text { Phonological verbal fluency } \\
\text { (Carlesimo et al., 1996) } \\
\text { Backward span (Monaco } \\
\text { et al., 2013) } \\
\text { Digits } \\
\text { Spatial blocks }\end{array}$ & $\begin{array}{c}14 " / 0 \\
18^{\prime \prime} / 0 \\
38^{\prime \prime} / 0 \\
22^{\prime \prime}(>50 \% 0) \\
0(=100 \% 0) \\
41.2(=100 \% 0) \\
3.3(>10 \% 0) \\
6.4(=100 \% 0)\end{array}$ & $\begin{array}{c}12^{\prime \prime} / 0 \\
22 " / 0 \\
36 " / 0 \\
16^{\prime \prime}(>50 \% 0) \\
0(=100 \% 0) \\
39,0(=100 \% 0) \\
3.3(>10 \% 0) \\
5.4(=100 \% 0)\end{array}$ & $\begin{array}{c}14 " / 0 \\
20 " / 0 \\
30 " / 0 \\
13^{\prime \prime}(>50 \% 0) \\
0(=100 \% 0) \\
41,0(=100 \% 0) \\
3.3(>10 \% 0) \\
5.4(=100 \% \circ)\end{array}$ & & $\begin{aligned}-<36.92 \\
<4.24 \\
>17.4 \\
>2.6 \\
>3.2\end{aligned}$ \\
\hline Praxic abilities & $\begin{array}{l}\text { Copy of drawings (Carlesimo } \\
\text { et al., 1996) } \\
\text { Free copy } \\
\text { Copy with landmarks }\end{array}$ & $\begin{array}{l}12(=100 \% 0) \\
70(=100 \% 0)\end{array}$ & $\begin{array}{l}12(=100 \% 0) \\
70(=100 \% 0)\end{array}$ & $\begin{array}{l}12(=100 \%) \\
70(=100 \% 0)\end{array}$ & $\begin{array}{l}12 \\
70\end{array}$ & $\begin{array}{r}>7.2 \\
>61.9\end{array}$ \\
\hline Language & $\begin{array}{l}\text { Naming Test (Miceli, } \\
\quad \text { Laudanna, Burani, \& } \\
\text { Capasso, 1994) } \\
\text { Objects } \\
\text { Actions }\end{array}$ & $\begin{array}{l}29(>75 \% 0) \\
28(=100 \% 0)\end{array}$ & $\begin{array}{l}29(>75 \% 0) \\
28(=100 \% 0)\end{array}$ & $\begin{array}{l}30(=100 \% 0) \\
28(=100 \% 0)\end{array}$ & $\begin{array}{l}30 \\
28\end{array}$ & $\begin{array}{l}28 \\
26\end{array}$ \\
\hline
\end{tabular}

recognized item, a subjective judgement of the memory process (whether recollection or familiarity), which had prompted the "old" response. For this purpose, we used the Remember/ Know paradigm (R/K; devised by Tulving, 1985), which is widely used in the experimental literature to test individuals with memory disorders (e.g., Turriziani et al., 2008; Yonelinas et al., 1998). Specifically, for each item that was judged as "old" (i.e., present on the study list) the experimental subjects were instructed to respond "remember" if they had a vivid memory of the specific episode in which the item had been previously presented. Instead, they were told to respond "know" if they felt the item had been presented during the study phase, but could not recollect the specific episode during which it had been previously presented.

For the verbal version of the test, we selected 240 Italian words from the CoLFIS database (Bertinetto et al., 2005). The words were divided into two sets of 120 words each, one set to be studied and successively recognized and the other set to be used as filler in the recognition test. Each set was in turn divided into four, 30-word subsets; the eight subsets were comparable for frequency of occurrence, concreteness and familiarity according to the CoLFIS database (Bertinetto et al., 2005). By coupling a subset of the target set and a subset of the filler set, we obtained four different versions of the Recognition test. 
For the visual version of the test, instead, 240 black and white photos of human faces (120 males, 120 females) were selected. Also in this case, the faces were divided into two sets of 120 each (60 males, 60 females) and each set was in turn divided into four subsets of 30 faces each with an equal number of males and females represented. Again, by coupling a subset of the target set and a subset of the filler set, we obtained four different versions of the Recognition test.

Analogous testing procedures were followed for the verbal and the visual recognition tests. During the study phase, experimental subjects were individually shown a set of 120 words or faces on a PC screen and asked to remember them. They were exposed to each item for $3 \mathrm{sec}$. and required to make a judgment about its pleasantness on a Likert scale that ranged from 0 to 4 (0: I do not like it at all; 1: I do not like it; 2: I am indifferent to it; 3: I like it; 4: I really like it). Recognition of the studied material was tested $10 \mathrm{~min} ., 30 \mathrm{~min}, 1 \mathrm{hr}$ and 7 days after completion of the study phase. In each recognition test, 30 words or faces forming a subset of the studied set and 30 words or faces forming a subset of the unstudied set were presented in random order and the subjects were asked to answer "old" to items they remembered having seen previously and "new" to items they did not remember having seen. If an item was judged as "old", the subject was further required to report whether it was recollected ("remember") or whether it was just felt to be familiar ("know"). For each recognition test, different subsets of target and filler items were used. The two tests were given on the same days. The first day, the study phase and the $10 \mathrm{~min}$., $30 \mathrm{~min}$ and $1 \mathrm{hr}$ delayed recognition tests of the verbal version were given; 30 min later, they were followed by the study phase and the first three recognition tests of the visual version. The participant was at this point debriefed and given a new appointment one week later for a final memory test (without specifying that it still would have regarded the word and/or the face lists). In the last testing session (7 days after), the verbal recognition test was given as first followed, 30 min later, by the visual test.

The estimates of recollection and familiarity were calculated according to Yonelinas et al. (1998). Recollection was evaluated in terms of the probability of "Remember" responses. The recollection scores were calculated by subtracting the proportion of false alarms from the proportion of correct "remember" response and then dividing this number by the probability of obtaining a true "remember" response, $\mathrm{R}=$ (Rold-Rnew)/(1-Rnew). Conversely, familiarity reflects a process of signal detection and is measured in terms of $d$. "It is calculated as the probability of giving a 'Know' response to an old item, Fold = Kold/(1-Rold), and the probability of giving the same response incorrectly to a new item, Fnew = Knew/(1-Rnew). Subsequently, the familiarity estimate is converted to $d^{\prime \prime}$.

EF's performances on the Word and Face recognition tests were compared with those of 18 healthy controls (NC) matched for sex (all women), age $(M=36.1 ; S D=2.4$; $\mathrm{t}=0.36 ; p=.72$ ) and years of formal education (all graduated with a university degree).

The experimental protocol was approved by the Ethics Committee of the S. Lucia Foundation. The patient and the control subjects gave their written informed consent to participate in the study.

\subsection{Results}

For each test we analyzed overall recognition accuracy ("old" correct minus "old" incorrect; maximum score = 30), irrespective of whether the participants subjectively qualified the "old" responses as "remember" or "know" at the four delay intervals. Then we compared separately the recollection estimates and the familiarity estimates at all delay intervals. To test the decrement in memory performance (taking into account the initial level of recognition accuracy), we computed the percentage of the amount retained passing from the earliest delay (10 $\mathrm{min}$ ) to the successive ones (30 $\mathrm{min}, 1 \mathrm{hr}$ and 7 days). Given the non-linear relationship between the $d$ metric and the number of hit rates and correct rejections for the different accuracy levels, we could not compute a similar percentage of retention for the familiarity estimate. In this case, we calculated the amount retained as the difference between $\mathrm{d}$ scores on the $30 \mathrm{~min}, 1 \mathrm{hr}$ and seven day tests as compared with the d score on the $10 \mathrm{~min}$ test.

To compare EF's and NCs' performance on the Word and Face recognition tests, we used the Crawford and Garthwaite (2002) procedure. This approach uses a formula provided by Sokal and Rohlf (1995) that treats the performance of the control sample as statistics (rather than as population parameters) and uses the t-distribution (rather than the standard normal distribution) to evaluate the abnormality of the individual's scores. This approach tests whether an individual's score is different from that of a control sample at a significance level set at 0.05 . The effect size of the significant comparisons was expressed as $z_{c c}$. This index is an estimate of the average difference, measured in standard deviation units, between a case's score and the score of a randomly chosen member of the control population. Like Cohen's $d, z_{c c}$ is insensitive to the size of the control sample (Crawford, Garthwaite, \& Porter, 2010).

\subsubsection{Word recognition test}

As reported in Figure 2 (panel A), EF's overall performance accuracy on the Word recognition test was in the range of that of NCs at all delays. Indeed, no significant difference in recognition accuracy was found at the 10 min: $\mathrm{t}=0.13, p=.44$; 30 min: $\mathrm{t}=0.32, p=.38$; and 7 days: $\mathrm{t}=0.26, p=.40$ intervals and it only approached significance at the $1 \mathrm{hr}$ interval: $t=1.43, p=.09$. As a consequence, the percentage of the amount retained by EF did not differ from that of NCs at all delays (Figure 2, panel D), 30 min: $\mathrm{t}=0.86, p=.20 ; 1 \mathrm{hr}$ : $\mathrm{t}=1.27, p=.11 ; 7$ days: $\mathrm{t}=0.29, p=.39$.

As reported in Figure 2 (panel B), NCs average recollection estimates decreased somewhat within $1 \mathrm{hr}$ and much more on the seven day tests. EF's recollection overlapped NCs average on the 10 min and 30 min tests, but declined strikingly thereafter becoming considerably worse than those of NCs on the $1 \mathrm{hr}$ and seven day tests. Thus, the statistical comparison did not show any significant differences for the $10 \mathrm{~min}, \mathrm{t}=0.49$, $p=.32$, or the $30 \mathrm{~min}, \mathrm{t}=0.06, p=.48$, tests. Conversely, the difference was significant on the $1 \mathrm{hr}$ test, $\mathrm{t}=3.97, p=.004$, $z_{c c}=-4.1(-5.5$ to -2.6$)$, and on the seven day test, $t=1.81$, $p=.04, z_{c c}=-1.7(-2.5$ to -0.1$)$. The percentage of the amount retained (Figure 2, panel E) passing from the $10 \mathrm{~min}$ to the 30 min test was similar in EF and NCs, $\mathrm{t}=0.88, p=.20$. 


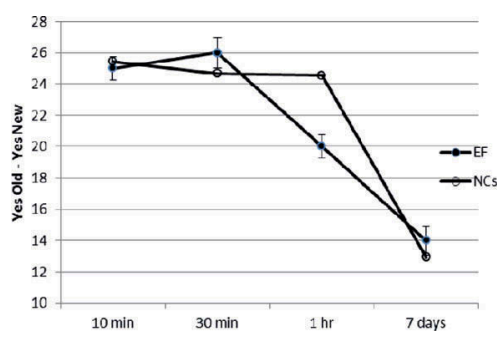

d

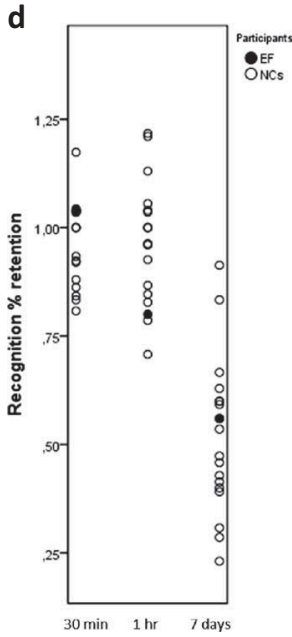

b

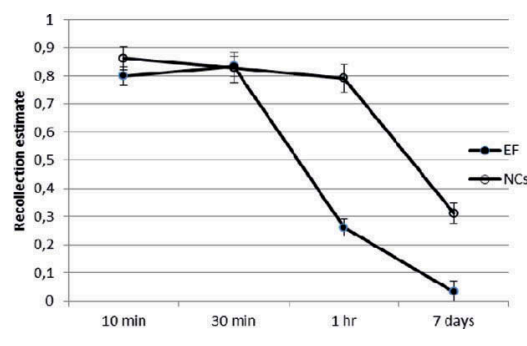

e

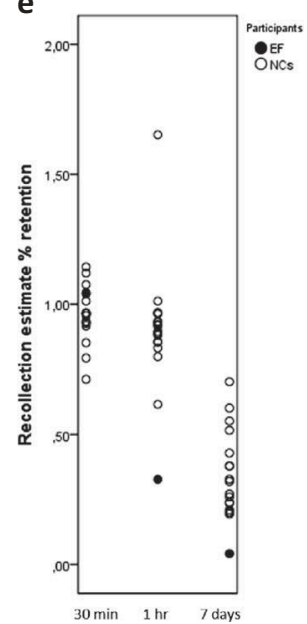

C

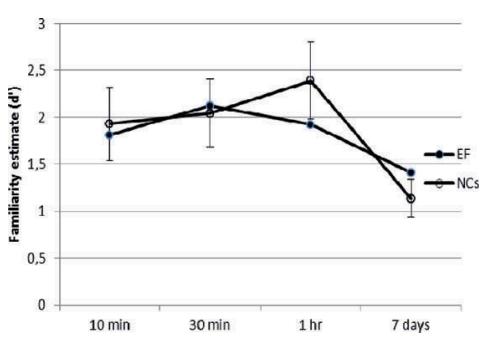

$\mathbf{f}$

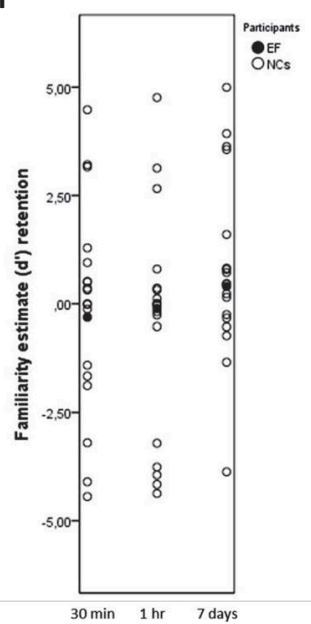

Figure 2. Performance of EF and NCs at the four delay intervals of the Word Recognition test (bars represent standard errors). Panel A shows the overall recognition accuracy (irrespectively of whether the participants subjectively qualified the "old" responses as "remember" or "know") calculated as "old" correct minus "old" uncorrect. Panel B reports the Recollection estimates and Panel C the familiarity estimates calculated according to Yonelinas et al. (1998). Panels D, E and F show a plot of the amount retained by each individual (i.e., EF and NCs) passing from the earliest delay (10 min) to the successive ones ( $30 \mathrm{~min}, 1 \mathrm{hr}$ and 7 days), respectively for overall recognition accuracy, and Recollection and Familiarity estimates.

Conversely, the percentage retained by EF on the following intervals was considerably lower than that of any NC. Accordingly, the difference was statistically significant on the $1 \mathrm{hr}, \mathrm{t}=2.97, p=.004, \mathrm{z}_{\mathrm{cc}}=-3.0(-4.2$ to -1.9$)$ and the seven day, $\mathrm{t}=2.01, p=.03, \mathrm{z}_{\mathrm{cc}}=-1.9(-2.7$ to -1.1$)$ tests.

In a final analysis, we compared familiarity estimates derived from the word recognition test. As shown in Figure 2 (panel C), NCs did not show any appreciable decrement as a function of the elapsed time. EF obtained scores that were mostly in the range of NCs at all delays which were assessed. Indeed, her familiarity scores did not differ from those of NCs on the $10 \mathrm{~min}, \mathrm{t}=0.06 p=.48,30 \mathrm{~min}$, $\mathrm{t}=0.05, p=.48,1 \mathrm{hr}, \mathrm{t}=0.26, p=.40$, or seven day, $\mathrm{t}=0.32, p=.38$, tests. Accordingly, the amount retained by EF did not differ from that of NCs at all delays: $30 \mathrm{~min}, \mathrm{t}=0.08$, $p=.47,1 \mathrm{hr}, \mathrm{t}=0.13, p=.45$, and seven day, $\mathrm{t}=0.18, p=.43$, (Figure 2, panel F).

\subsubsection{Face recognition test}

Also in this case, we first compared EF's and NCs' overall recognition accuracy. As reported in Figure 3 (panel A), NCs' performance accuracy declined slightly within $1 \mathrm{hr}$ and considerably more on the seven day test. EF's recognition accuracy was somehow less regular than the NC average. However, EF's and NCs' recognition scores did not differ significantly at any delay, $10 \min , \mathrm{t}=0.78, p=.22,30 \min , \mathrm{t}=0.34, p=.37$, $1 \mathrm{hr}, \mathrm{t}=0.60, p=.28,7$ days, $\mathrm{t}=0.73, p=.24$. Thus, the percentage of the amount retained on the $30 \mathrm{~min}, \mathrm{t}=1.14$, $p=.14,1 \mathrm{hr}, \mathrm{t}=0.01, p=.50$, and seven day, $\mathrm{t}=1,58, p=.0,7$ tests was comparable (Figure 3, panel D).

As shown in Figure 3 (panel B), NCs recollection estimates on the visual test declined as a function of time. Indeed, recollection decreased slightly in the first hour and considerably more on the seven day test. EF's recollection estimates were consistently poorer than NCs, irrespective of the delay considered. However, while the statistical comparison did not show a statistically significant difference at the $10 \mathrm{~min}$, $\mathrm{t}=1.03, p=.16$, and the $30 \mathrm{~min}, \mathrm{t}=1.28, p=.11$, tests, it approached significance on the $1 \mathrm{hr}, \mathrm{t}=1.76, p=.05$, and the seven day, $\mathrm{t}=1.49, p=.08$, tests. EF's percentages retained were in the lower segment of the NCs range on the $30 \mathrm{~min}$ and $1 \mathrm{hr}$ test and slightly outside this range on the seven day test (Figure 3, panel E). In this case the statistical comparisons did not show any difference at the 30 min test, $t=0.97$, $p=.17$, but approached significance at the $1 \mathrm{hr}, \mathrm{t}=1.68$, $p=.06$, and seven day, $\mathrm{t}=1.46, p=.08$, tests.

As for familiarity on the face recognition test (Figure 2, panel C), NC's estimates declined significantly passing from the $10 \mathrm{~min}$ to the $30 \mathrm{~min}$ test but thereafter remained quite stable. EF's familiarity estimates were consistently similar (or even higher) than those of the control group. Thus, the statistical comparison did not show any significant difference on the $10 \mathrm{~min}, \mathrm{t}=0.69, p=.25$, the $30 \mathrm{~min}, \mathrm{t}=1.40, p=.09$, the $1 \mathrm{hr}, \mathrm{t}=0.05, p=.48$, or the seven day, $\mathrm{t}=0.76, p=.23$, test. 
a

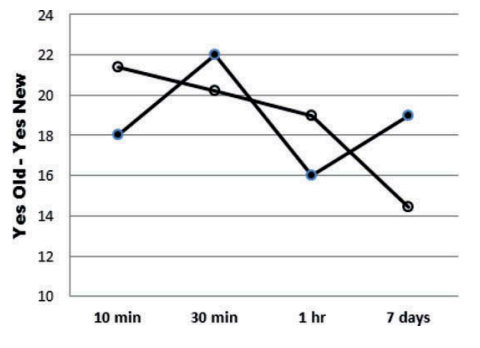

d

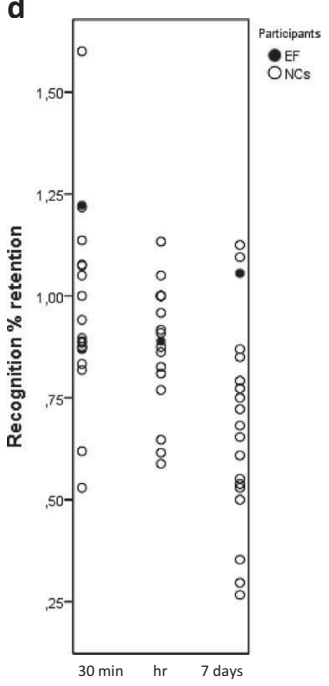

b
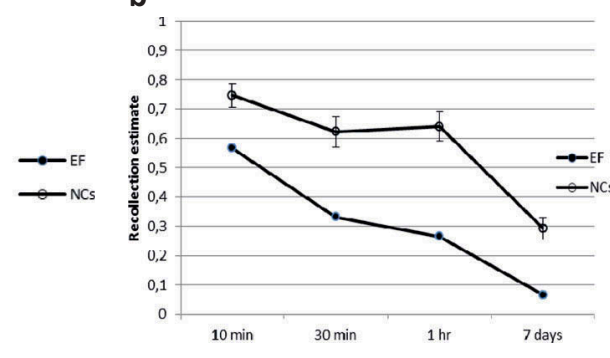

e

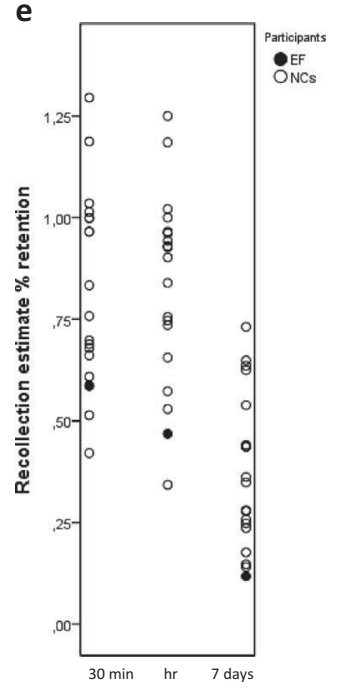

C

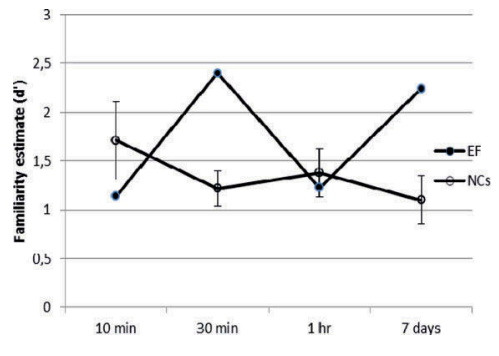

f

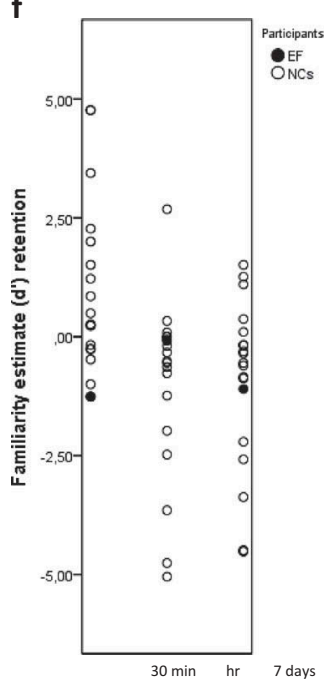

Figure 3. Performance of EF and average performance of NCs at the four delay intervals of the Face Recognition test (bars represent standard errors). Panel A shows the overall recognition accuracy (irrespectively of whether the participants subjectively qualified the "old" responses as "remember" or "know") calculated as "old" correct minus "old" uncorrect. Panel B reports the Recollection estimates and Panel C the familiarity estimates calculated according to Yonelinas et al. (1998). Panels $\mathrm{D}, \mathrm{E}$ and $\mathrm{F}$ show a plot of the amount retained by each individual ( $\mathrm{EF}$ and NCs) passing from the earliest delay (10 min) to the successive ones (30 min, $1 \mathrm{hr}$ and 7 days), respectively for overall recognition accuracy, Recollection and Familiarity estimates.

Likewise, differences in the amount retained on the $30 \mathrm{~min}$, $\mathrm{t}=1.24, p=.11,1 \mathrm{hr}, \mathrm{t}=0.50, p=.31$, and seven day, $\mathrm{t}=0.10$, $p=.46$, tests did not approach significance.

\section{Discussion}

Here we report the case of $E F$, a patient with a drug-resistant TLE syndrome, which complained memory difficulties characterized by accelerated forgetting of recent events. Repeated assessments of episodic memory functioning with commonly used neuropsychological tests consistently documented normal performances in this patient. Conversely, administration of two experimental tests, that assessed recognition memory for verbal and visual information over delays ranging from $10 \mathrm{~min}$ to 7 days and that provided estimates of recollection and familiarity, documented a peculiar pattern of memory impairment in EF. Indeed, overall performance accuracy on recognition tests for both verbal and visual material (irrespectively of whether participants subjectively judged the "old" response as generated by recollection or familiarity memory processes) did not clearly differentiate EF from NCs at all testing delays. However, when performance on the recognition tests was further analyzed in order to take into account for the contribution of recollection and familiarity to overall recognition accuracy, EF disclosed an impairment of the recollection component with intact familiarity processes. The peculiarity of this patient with respect to previously reported patients with ALF is that EF did not show increased forgetting in the overall recognition performance (as it is typical in these patients), but only when the two components of recognition were evaluated separately. Indeed, it was the adoption of a recognition paradigm aimed to assess separately the two components of recognition that allowed disclosing in EF a recognition pattern characterized by an accelerated forgetting for the recollection component only.

The EF's recollection deficit, however, quite differed depending on the verbal or visual nature of the material to be remembered. As for verbal material, experimental data are straightforward in revealing a normal early acquisition but an accelerated forgetting rate at longer delays of the recollection component of recognition. EF's performance, in fact, was very close to the average NCs performances on the earliest tests (10 and 30 min delays), but declined strikingly thereafter, scoring significantly poorer than NCs on the $1 \mathrm{hr}$ test and reaching the floor of the score range on the seven day test. Thus, the patient's percentage retained on the $1 \mathrm{hr}$ and seven day tests was significantly smaller than that of the NCs retained. In the visual modality, by contrast, the recollection pattern of impairment was less clear. Here, in fact, the difference between EF's and NCs' performance did not reach the level of significance of formal statistics at any delay. However, 
only one normal control retained less than EF at the $1 \mathrm{hr}$ (as compared to the $10 \mathrm{~min}$ ) assessment whereas no healthy subject's percentage of retention was worse than that of EF on the seven day test.

In summary, to the best of our knowledge, this is the first description of a patient with an ALF syndrome confined to the recollection component of recognition memory with the complete sparing of familiarity. This performance profile was straightforward in the verbal domain, where the amnesic pattern disclosed by our patient was characterized by a selective ALF of recollection data. Also in the visual domain our patient showed an increased forgetting rate for the recollection component only. In this case, however, results are not conclusive, since this effect did not reach the statistical significance at any delay.

We interpret the memory impairment disclosed by EF according to the above mentioned dual-process theory which posits that the hippocampus underlies recollection and, conversely, that the parahippocampal cortices (particularly the perirhinal cortex) is responsible for familiarity (e.g., Aggleton et al., 2005; Montaldi \& Mayes, 2010; Turriziani et al., 2008; Yonelinas et al., 1998). Indeed, the crucial anatomical damage (FCD) in EF was localized in the right hippocampus and the resulting epileptic abnormalities had presumably a hippocampal origin. On the other side, EEG recordings documented the contralateral diffusion of bioelectrical abnormalities in the left temporal lobe. Since such diffusion may occur via commissural fibres that connect homologous structures of the two hemispheres (Suárez, Gobius, \& Richards, 2014), we presume that such abnormalities disrupted the activity of the hippocampal circuitry in the left hemisphere as well. Accordingly, EF suffered of an ALF which was selective for recollection memory traces. Consistent with the bilaterality of bioelectrical abnormalities, the increased forgetting was straightforward for the verbal material, but it also affected recognition of visual material (even though at a non significant level).

A limit of the present study is obviously represented by the fact that the collected findings come from a unique TLE patient and this reduces the possibility of generalization. Another limit concerns the utilization of a unique procedure to evaluate the contribution of recollection and familiarity processes to the recognition performance; in order to evaluate data consistency, future studies should adopt a variety of paradigms (e.g., process dissociation procedure and receiver operating characteristic data). Finally, at least for the overall recognition and recollection estimate scores, the adopted procedure resulted in near floor effect of performance, thus possibly obscuring significant differences between controls' and patient scores to emerge.

In conclusion, we have documented for the first time a patient with TLE who showed an ALF confined to the recollection component of recognition memory processes. The subjective complaint of marked day-to-day memory difficulties was most likely due to such impairment. In this patient, memory tests commonly used in clinical practice could not detect any memory impairment, because such tests do not envisage a $1 \mathrm{hr}$ delay between presentation and recognition of stimuli and because they are not aimed at taking apart the contribution of recollection and familiarity processes to the recognition performance. Further studies are needed in order to better investigate the possible occurrence in TLE patients of ALF for recollective and, possibly, familiarity memory processes and to relate this deficit to clinical variables, neurophysiological markers of bioelectrical abnormality and neuroradiological indexes of damage localization which might shed light on possible mechanisms of the accelerated forgetting.

\section{Note}

1. It should be noted that the dual process theory as applied to recollection and familiarity processes is not universally accepted. Indeed, advocates of the single-process theory support the view that the psychological experiences of recollection and familiarity are actually the subjective expressions of recognition memory processes resulting from memory traces of variable strength. Neuropsychological evidence in patients with amnesia (e.g., Wais, Wixted, Hopkins, \& Squire, 2006) and functional neuroimaging data in healthy subjects (e.g., Song, Jeneson, \& Squire, 2011) support this view.

\section{Disclosure statement}

No potential conflict of interest was reported by the authors.

\section{Funding}

This work was supported by Italian Ministry of Health, ID - RRC-2016- 2361114.

\section{References}

Aggleton, J. P., Vann, S. D., Denby, C., Dix, S., Mayes, A. R., Roberts, N., \& Yonelinas, A. P. (2005). Sparing of the familiarity component of recognition memory in a patient with hippocampal pathology. Neuropsychologia, 43, 1810-1823. doi:10.1016/j.neuropsychologia.2005.01.019

Barr, W. B. (1997). Examining the right temporal lobe's role in nonverbal memory. Brain and Cognition, 35, 26-41. doi:10.1006/brcg.1997.0925

Bertinetto, P. M., Burani, C., Laudanna, A., Marconi, L., Ratti, D., Rolando, C., \& Thornton, A. M. (2005). Corpus e lessico di frequenza dell'italiano scritto (CoLFIS). http://linguistica.sns.it/CoLFIS/Home.htm

Blake, R. V., Wroe, S. J., Breen, E. K., \& McCarthy, R. A. (2000). Accelerated forgetting in patients with epilepsy: Evidence for an impairment in memory consolidation. Brain, 123, 472-483. doi:10.1093/brain/ 123.3.472

Butler, C. R, \& Zeman, A. Z. (2008). Recent insights into the impairment of memory in epilepsy: transient epileptic amnesia, accelerated long-term forgetting and remote memory impairment. Brain, 131, 2243-2263. doi:10.1093/brain/awn127

Caffarra, P., Vezzadini, G., Dieci, F., Zonato, F., \& Venneri, A. (2002). ReyOsterrieth complex figure: Normative values in an Italian population sample. Neurological Sciences, 22, 443-447. doi:10.1007/s100720200003

Carlesimo, G. A., Caltagirone, C., \& Gainotti, G. (1996). The mental deterioration battery: Normative data, diagnostic reliability and qualitative analyses of cognitive impairment. The group for the standardization of the mental deterioration battery. European Neurology, 36, 378-384. doi:10.1159/000117297

Cassel, A., Morris, R., Koutroumanidis, \& Kopelman, M. (2016). Forgetting in temporal lobe epilepsy: When does it become accelerated? Cortex, 78, 70-84. doi:10.1016/j.cortex.2016.02.005

Crawford, J. R., \& Garthwaite, P. H. (2002). Investigation of the single case in neuropsychology: Confidence limits on the abnormality of test scores and test score differences. Neuropsychologia, 40, 1196-1208. doi:10.1016/S0028-3932(01)00224-X

Crawford, J. R., Garthwaite, P. H., \& Porter, S. (2010). Point and interval estimates of effect sizes for the case-controls design in 
neuropsychology: Rationale, methods, implementations, and proposed reporting standards. Cognitive Neuropsychology, 27, 245-260. doi:10.1080/02643294.2010.513967

Davidson, M, Dorris, L, O'Regan, M, \& Zuberi, S.M. (2007). Memory consolidation and accelerated forgetting in children with idiopathic generalized epilepsy. Epilepsy \& Behavior, 11, 394-400. doi:10.1016/j. yebeh.2007.05.004

Elliott, G., Isaac, C. L., \& Muhlert, N. (2014). Measuring forgetting: A critical review of accelerated long-term forgetting studies. Cortex, 54, 16-32. doi:10.1016/j.cortex.2014.02.001

Fitzgerald, Z., Mohamed, A., Ricci, M., Thayer, Z., \& Miller, L. (2013). Accelerated long-term forgetting: A newly identified memory impairment in epilepsy. Journal of Clinical Neuroscience, 20, 1486-1491. doi:10.1016/j.jocn.2013.04.037

Freed, D. M., \& Corkin, S. (1988). Rate of forgetting in H.M.: 6-month recognition. Behavioural Neuroscience, 102, 823-827. doi:10.1037/07357044.102.6.823

Huppert, F. A., \& Piercy, M. (1978). Dissociation between learning and remembering in organic amnesia. Nature, 275, 317-318. doi:10.1038/ $275317 \mathrm{a} 0$

Insausti, R., Annese, J., Amaral, D. G., \& Squire, L. R. (2013). Human amnesia and the medial temporal lobe illuminated by neuropsychological and neurohistological findings for patient E.P. Proceedings of the National Academy of Science of the United States of America, 110, E1953-1962. doi:10.1073/pnas.1306244110

Lee, T. M., Yip, J. T., \& Jones-Gotman, M. (2002). Memory deficits after resection from left or right anterior temporal lobe in humans: A metaanalytic review. Epilepsia, 43, 283-291. doi:10.1046/j.15281157.2002.09901.x

Lezak, M., Howieson, M., \& Loring, D. (2004, 2004). Neuropsychological Assessment. (4th ed). New York: Oxford University Press

Lucchelli, F., \& Spinnler, H. (1998). Ephemeral new traces and evaporated remote engrams: A form of neocortical temporal lobe amnesia? A preliminary case report. Neurocase, 6, 447-459. doi:10.1080/ 13554799808410638

Manes, F, Graham, K. S, Zeman, A, de Luján Calcagno, M, \& Hodges, J. R. (2005). Autobiographical amnesia and accelerated forgetting in transient epileptic amnesia. Journal Of Neurology, Neurosurgery \& Psychiatry, 76, 1387-1391. doi:10.1136/jnnp.2004.036582

Mayes, A. R., Isaac, C. L., Holdstock, J. S., Cariga, P., Gummer, A., \& Roberts, N. (2003). Long-term amnesia: A review and detailed illustrative case study. Cortex, 39, 567-603. doi:10.1016/S0010-9452(08)70855-4

McKee, R. D., \& Squire, L. R. (1992). Equivalent forgetting rates in long-term memory for diencephalic and medial temporal lobe amnesia. Journal of Neuroscience, 12, 3765-3772.

Miceli, G., Laudanna, A., Burani, C., \& Capasso, R. (1994). Batteria per I'analisi dei deficit afasici. B.A.D.A. Roma: CEPSAG.

Milner, B. (1968). Disorders of memory after brain lesions in man: Preface: Material-specific and generalized memory loss. Neuropsychologia, 6, 175-179. doi:10.1016/0028-3932(68)90017-1

Monaco, M., Costa, A., Caltagirone, C., \& Carlesimo, G. A. (2013). Forward and backward span for verbal and visuo-spatial data: Standardization and normative data from an Italian adult population. Neurological Sciences, 34, 749-754. doi:10.1007/s10072-012-1130-x
Montaldi, D., \& Mayes, A. R. (2010). The role of recollection and familiarity in the functional differentiation of the medial temporal lobes. Hippocampus, 20, 1291-1314. doi:10.1002/hipo.20853

Montaldi, D., Spencer, T. J., Roberts, N., \& Mayes, A. R. (2006). The neural system that mediates familiarity memory. Hippocampus, 16, 504-520. doi:10.1002/(ISSN) 1098-1063

Skinner, E. l., \& Fernandes, M. A. (2007). Neural correlates of recollection and familiarity: A review of neuroimaging and patient data. Neuropsychologia, 45, 2163-2179. doi:10.1016/j.neuropsychologia.2007.03.007

Smirni, D., Turriziani, P., Olivieri, M., Smirni, P., \& Cipollotti, L. (2010). Standardizzazione di tre nuovi test di memoria di riconoscimento verbale e non verbale: Uno studio preliminare. Giornale Italiano Di Psicologia, 1, 227-248.

Sokal, R. R., \& Rohlf, F. J. (1995). Biometry: The principles and practice of statistics in biological research. San Francisco W. H: Freeman.

Song, Z., Jeneson, A., \& Squire, L. R. (2011). Medial temporal lobe function and recognition memory: A novel approach to separating the contribution of recollection and familiarity. Journal of Neuroscience, 31, 1602616032. doi:10.1523/JNEUROSCI.3012-11.2011

Spinnler, H., \& Tognoni, G. (1987). Standardizzazione e taratura italiana di test neuropsicologici. Italian Journal of Neurological Sciences, Suppl 8 , $1-20$.

Suárez, R., Gobius, I., \& Richards, L. J. (2014). Evolution and development of interhemispheric connections in the vertebrate forebrain. Frontiers in Human Neuroscience, 8, 497. doi:10.3389/fnhum.2014.00497

Tramoni, E., Felician, O., Barbeau, E. J., Guedj, E., Guye, M., Bartolomei, F., \& Ceccaldi, M. (2011). Long-term consolidation of declarative memory: Insight from temporal lobe epilepsy. Brain, 134, 816-831. doi:10.1093/ brain/awr002

Tschampa, H. J., Urbach, H., Träber, F., Sprinkart, A. M., Greschus, S., Malter, M. P., ... Block, W. (2015). Proton magnetic resonance spectroscopy in focal cortical dysplasia at 3T. Seizure, 32, 23-29. doi:10.1016/j. seizure.2015.08.008

Tulving, E. (1985). Memory and consciousness. Canadian Psychological Association, 73, 540-549.

Turriziani, P., Serra, L., Fadda, L., Caltagirone, C., \& Carlesimo, G. A. (2008). Recollection and familiarity in hippocampal amnesia. Hippocampus, 18, 469-480. doi:10.1002/hipo.20412

Valgimigli, S., Padovani, R., Budriesi, C., Leone, M. E., Lugli, D., \& Nichelli, P. (2010). Test di Stroop: Dati normativi italiani di una versione cartacea per I'uso clinico. Giornale Italiano Di Psicologia, 4, 945-956.

Wais, P. E., Wixted, J. T., Hopkins, R. O., \& Squire, L. R. (2006). The hippocampus supports both the recollection and the familiarity components of recognition memory. Neuron, 49, 459-466. doi:10.1016/j.neuron.2005.12.020

Wixted, J. T., Mickes, L., \& Squire, L. R. (2010). Measuring recollection and familiarity in the medial temporal lobe. Hippocampus, 20, 1195-1205. doi:10.1002/hipo.20854

Yonelinas, A. P. (2002). The nature of recollection and familiarity: A review of 30 years of research. Journal of Memory and Language, 46, 441-517. doi:10.1006/jmla.2002.2864

Yonelinas, A. P., Kroll, N. E., Dobbins, I., Lazzara, M., \& Knight, R. T. (1998). Recollection and familiarity deficits in amnesia: Convergence of remember-know, process dissociation, and receiver operating characteristic data. Neuropsychology, 12, 323-339. doi:10.1037/0894-4105.12.3.323 